\title{
Immune checkpoint inhibitors and prostate cancer: a new frontier?
}

\author{
Alessandra Modena, ${ }^{1}$ Chiara Ciccarese, ${ }^{1}$ Roberto lacovelli, ${ }^{1}$ Matteo Brunelli, ${ }^{2}$ \\ Rodolfo Montironi, ${ }^{3}$ Michelangelo Fiorentino, ${ }^{4}$ Giampaolo Tortora, ${ }^{1}$ Francesco Massari ${ }^{5}$ \\ ${ }^{1}$ Medical Oncology, University-Hospital of Verona, Verona; ${ }^{2}$ Department of Pathology and \\ Diagnostic, University-Hospital of Verona, Verona; ${ }^{3}$ Section of Pathological Anatomy, Polytechnic \\ University of Marche Region, School of Medicine, Ancona; ${ }^{4}$ Pathology Service, Addarii Institute of \\ Oncology, S. Orsola-Malpighi Hospital, Bologna; ${ }^{5}$ Division of Oncology, S. Orsola-Malpighi \\ Hospital, Bologna, Italy
}

\begin{abstract}
Despite recent advances in the treatment of metastatic castrationresistant prostate cancer (mCRPC), agents that provide durable disease control and long-term survival are still needed. It is a fact that a tumor-induced immunosuppressive status (mediated by aberrant activation of inhibitory immune checkpoint pathways as a mechanism to evade host immune surveillance) plays a crucial role in the pathogenesis of cancer, including prostate cancer (PC), making CRPC patients suitable candidates for immunotherapy. Therefore, growing interest of anticancer research aims at blocking immune checkpoints (mainly targeting CTLA-4 and PD1/PD-L1 pathways) to restore and enhance cellular-mediated antitumor immunity and achieve durable tumor regression. In this review, we describe the current knowledge regarding the role of immune checkpoints in mediating PC progression, focusing on CTLA-4 and PD1 pathways. We also provide current clinical data available, an update on ongoing trials of immune checkpoint inhibitors in PC. Finally, we discuss the necessity to identify prognostic and predictive biomarkers of immune activity, and we analyze new immune checkpoints with a role as promising targets for PC therapy.
\end{abstract}

Correspondence: Francesco Massari, Division of Oncology, S. OrsolaMalpighi Hospital, via Pietro Albertoni 15, 40138 Bologna, Italy.

E-mail: fmassari79@gmail.com

Key words: Prostate cancer; immunotherapy; immune checkpoint inhibitors; CTLA-4; PD-1; PD-L1.

Contributions: AM, CC contributed equally.

Conflict of interest: the authors declare no potential conflict of interest.

Received for publication: 1 March 2016.

Accepted for publication: 23 March 2016.

This work is licensed under a Creative Commons Attribution NonCommercial 4.0 License (CC BY-NC 4.0).

(C) Copyright A. Modena et al., 2016

Licensee PAGEPress, Italy

Oncology Reviews 2016; 10:293

doi:10.4081/oncol.2016.293

\section{Introduction}

Prostate cancer (PC) is the second most commonly diagnosed malignant tumor in men and a major cause of mortality, with an estimated 385,560 deaths globally expected in $2020 .{ }^{1}$ In the last few years, the identification and the approval of several agents for the treatment of metastatic castration-resistant prostate cancer (mCRPC), including cytotoxic drugs (cabazitaxel), ${ }^{2}$ second-generation anti-androgen compounds (abiraterone acetate and enzalutamide) ${ }^{3-6}$ and particles emitting radionuclides (radium-223), ${ }^{7}$ has rapidly changed the therapeutic armamentarium and the natural history of this disease, prolonging survival and maintaining patients' life quality. Despite these progresses, mCRPC remains a disease with a lethal outcome that still requires new treatments to provide durable disease control and to improve patients' outcomes. Several therapeutic strategies are currently under investigation; anticancer immunotherapy is becoming significantly relevant also in PC. In particular, increasing the host's immune response against PC cells could represent a valid and promising therapeutic approach.

Tumor development and progression result from a cancer-induced immunosuppressive status, in which the patient's immune system is not able to recognize and destroy neoplastic cell clones because cancer cells are able to elude the anti-tumor immune response (cancer immunoediting), hence becoming resistant to immune surveillance. Immune evasion is therefore recognized as a hallmark feature of cancer. ${ }^{8,9}$ Among different mechanisms involved in cancer immune escape, immune checkpoints have a key role. Immune checkpoint pathways [including mainly two immunomodulatory receptors expressed on T-cells - cytotoxic T lymphocyte antigen-4 (CTLA-4) and programmed death-1 (PD-1) - and their corresponding ligands - B71/B7-2 and PD-L1, respectively] physiologically dampen T-cell activity, being crucial for minimizing inflammatory-dependent tissue damage and maintaining self-tolerance. Cancer cells can over-express specific immune-checkpoint molecules, negatively regulating the immune system. Therefore, the activation of different inhibitory immune checkpoint pathways is a fundamental mechanism for the tumor cells' immune resistance, especially against T-cells. ${ }^{10}$ In recent years anticancer research focuses on immunotherapy, which aims at enhance antitumor immunity by blocking immune checkpoints. Monoclonal antibodies (mAbs) directed against CTLA-4 (ipilimumab) or PD-1/PDL1 (i.e., nivolumab, pembrolizumab, atezolizumab) can stimulate the immune system, reactivating T-cell proliferation and activity. This efficient strategy of checkpoint blockade represents one of the main oncological breakthroughs, with remarkable clinical durable responses and survival advantages observed in several cancer types. ${ }^{11}$

To date, sipuleucel-T (an autologous cellular immunotherapy) is the 
only approved immunotherapy for PC patients. ${ }^{12}$ However, the fundamental role of the patient's immune system in prostate cancerogenesis has led to further investigate several novel immunotherapeutic molecules, including vaccines (active immunotherapy) and immune checkpoint inhibitors (anti-CTLA-4 and anti-PD-1/PD-L1 mAbs), both alone or in combination with chemotherapy, androgen ablation or radiotherapy. ${ }^{13}$ We focused on the role of immune checkpoints (mainly CTLA-4 and PD1 pathways) in PC, with particular attention on the biological rationale, current clinical studies and future therapeutic perspectives.

\section{Immunosystem in prostate gland}

A strong immune rational supports the development of immunotherapy for PC. The lack of afferent lymphatics and the immunosuppressive properties of seminal fluid confer to the prostate gland an immunologically privileged status. Biologically, the majority of prostate tumors behave like a slow-growing disease, allowing time for a clinically relevant immune response and thus justifying the high immunogenicity of this tumor. ${ }^{14,15}$ PC cells, in fact, show an abnormal over-expression of several highly immunogenic tumor-associated antigens that represent potential target for immunotherapeutic approaches. ${ }^{16-18}$

Moreover, PC tissue is marked by a large inflammatory infiltrate of T-cells [tumor infiltrating lymphocytes (TILs)] within the tumor and in the surrounded microenvironment. ${ }^{19}$ Both the innate and the adaptive branches of the immune system participate in host defense mechanisms against neoplastic prostate cells. ${ }^{20}$ Macrophages/antigen-presenting cells (APCs), CD8+ cytotoxic T lymphocytes, CD4+ helper T lymphocytes, and natural killer (NK) cells should recognize and destroy cancer cells. Therefore, dense TILs infiltration seems to have a positive prognostic value, correlating with longer patient survival. ${ }^{21}$ Moreover, high grade prostatic adenocarcinomas have significantly less infiltration of T-cells as compared to benign nodular prostatic hyperplasia, ${ }^{22}$ underscoring that tumor progression could be associated with defects in cell-mediated immune responses.

The inability to mount an efficient immune response that restricts cancer progression is partially due to the presence of non-active effector TILs [lacking markers of functional activity like perforin or gammainterferon (IFN $\gamma$ )], ${ }^{23}$ and regulatory T-cells (Tregs) within the inflammatory infiltrate of PC tissue. Tregs is a small subpopulation of CD4+/CD25+ and CD8+/Foxp3 T lymphocytes with suppressive functions on the anti-immune response [directly via cell-cell contact or indirectly by secreting anti-inflammatory cytokines, like interleukin-10 (IL-10) or tumor growth factor (TGF $\beta)],{ }^{24,25}$ supposed to have a negative prognostic role in PC patients, ${ }^{26,27}$ highlighting that blockage of these cells may stimulate the generation of effective CD8+ T-cell immune responses and therefore induce beneficial clinical responses. ${ }^{28,29}$ In the end, hormonal therapies commonly used for PC treatment have immunomodulatory effects. Indeed, anti-androgens can activate thymic regeneration and promote thymopoiesis ${ }^{30}$ and B-cell proliferation, ${ }^{31}$ reduce intratumoral infiltration of immunosuppressive Tregs, mitigate tolerance to prostatic antigens, ${ }^{32}$ increase NK cell infiltrate, ${ }^{20}$ and induce high levels of T-cell infiltration (mainly CD4+ cells) within PC tissue,,$^{20,33}$ suggesting the potential role of combining immunotherapy with hormonal agents to enhance anticancer immune-based treatments. ${ }^{34}$

\section{Cytotoxic T-Iymphocyte-associated antigen-4}

CTLA-4 is a co-inhibitory receptor expressed on activated T CD4+ and CD8+ lymphocytes, which constrains T-cells activation by binding to B7-1 (CD80) and B7-2 (CD86) costimulatory molecules expressed on APCs more avidly than CD28 receptor (the main receptor required for T-lymphocytes activation). ${ }^{35,36}$ CTLA- 4 is also constitutively expressed on Tregs where it mediates their immune suppressive effects. ${ }^{37}$ These evidences suggested that CTLA-4 blockage could result in broad enhancement of antitumor immune responses, leading to the development of mAbs that specifically inhibit CTLA-4.

\section{Ipilimumab}

Ipilimumab is a fully human immunoglobulin G1 (IgG1) monoclonal antibody that blocks the activity of CTLA-4, enhancing the immune response in terms of T-cell activation. It is approved for the treatment of advanced melanoma and it is currently under investigation in various cancer types, including mCRPC.

Ipilimumab has been evaluated at different doses, schedules and combinations in mCRPC patients. Preclinical and clinical studies suggested that radiotherapy might cause immune-mediated tumor death and might induce tumor regression at locations far from the original site of irradiation (the abscopal effect) in an immune-mediated process. ${ }^{38}$ More interestingly, the combination of ipilimumab and conventional anticancer therapies results in a synergic antitumor activity, ${ }^{39-42}$ supporting the hypothesis that tumor antigens released during radiation-induced cell death may enhance the antitumor activity of ipilimumab. Based on this evidence, a phase I/II, non-randomized trial (CA184-107) of ipilimumab given alone or in combination with external-beam radiotherapy was performed in $\mathrm{MCRPC}$ patients who received no more than one prior chemotherapy, leading to prostate-specific antigen (PSA) decline in approximately $15 \%$ of cases. ${ }^{43}$ Similar results derived from a small randomized phase II trial using ipilimumab in combination with androgen deprivation therapy (ADT) versus ADT alone in advanced PC patients (undetectable PSA levels rate at 3 months of $55 \%$ versus $38 \%$, respectively), ${ }^{44}$ encouraging further evaluation in this context. A further improvement in biochemical tumor response rate up to $25-50 \%$ has been described with combination of ipilimumab with granulocyte-macrophage colony-stimulating factor or vaccines, without worsening ipilimumab-related side effects. ${ }^{45-48}$ Conversely, data from a small trial ipilimumab assessing in combination with a single dose of docetaxel versus ipilimumab alone failed to demonstrate a benefit from the addition of chemotherapy. ${ }^{49}$

Subsequently, a phase III randomized clinical trial (CA184-043) of a single dose of bone-directed radiotherapy followed by either ipilimumab at the dose of $10 \mathrm{mg} / \mathrm{kg}$ or placebo every 3 weeks for up to four cycles in CRPC patients with at least one bone metastasis who have progressed after docetaxel treatment, were performed. ${ }^{50}$ Although the primary end point of overall survival (OS) was not met, ipilimumab was associated with improved progression-free survival [4 months with ipilimumab versus 3.1 months with placebo; hazard ratio (HR) 0.70 ; $\mathrm{P}<0.0001]$ and in PSA response $(13.1 \%$ versus $5.2 \%)$. Moreover, data from pre specified and post hoc subgroup analysis suggested that ipilimumab might provide an OS benefit (modified OS 22.7 versus 15.8 months; HR 0.62, $\mathrm{P}=0038$ ) for patients with a better prognostic profile (i.e., no visceral metastases, alkaline phosphatase $<1.5$ times the upper limit of the normal range and hemoglobin $\geq 11 \mathrm{~g} / \mathrm{dL}$ ), particularly for those without visceral metastases, supporting further evaluation of ipilimumab in patients with a lower disease burden. The most common grade 3-4 immune-related adverse events were diarrhea (16\% in the ipilimumab group versus $2 \%$ in the placebo group), fatigue (11 versus $9 \%$ ), anemia (10 versus $11 \%$ ) and colitis (5 versus $0 \%$ ). Finally, it is important to underline that patients receiving ipilimumab seem to report delayed benefit in OS: whereas short-term OS did not differ between the ipilimumab and placebo arms, survival curves began to 
diverge after 5 months. This data suggest that continuing survival follow-up is warranted to draw strong conclusions and that the length of follow-up is fundamental to assess the sustainability of survival benefit of immune checkpoint inhibitors in mCRPC patients. Therefore, despite the benefit of ipilimumab in the post-docetaxel population was limited, its use in mCRPC should not be necessarily precluded until a better definition of the population to treat. ${ }^{51}$

Currently, new trials with ipilimumab alone or in combination are ongoing, including a phase III study in chemotherapy-naïve PC (CA184095 - NCT01057810) and neoadjuvant settings (NCT01194271). Since immunotherapy will be more effective in the early stages of disease, a significant $\mathrm{OS}$ benefit might be expected in these settings. ${ }^{52}$

\section{Tremelimumab}

Tremelimumab is a fully human IgG2 monoclonal antibody specific for CTLA-4, which is also undergoing clinical investigation in PC, in neoadjuvant and in recurrent disease. A phase I dose-escalation trial in PSA-recurrent PC demonstrated a prolongation in PSA doubling time in 3 of 11 patients several months after completing treatment with tremelimumab in combination with short-term ADT, with dose-limiting toxicities including grade G3 diarrhea and skin rash. ${ }^{53}$ The identification of delayed and prolonged decline in serum PSA suggests future explo- ration of this combination in patients with high risk for recurrence, so as to delay metastatic disease progression.

Tables $1^{38-44,47}$ and 2 summarize the completed phase I-III clinical trials and the selected ongoing studies of CTLA-4 inhibitors in PC, respectively.

Characteristically, anti-CTLA-4 clinical responses show a slow and delayed (up to 6 months after treatment initiation) onset's kinetic, with pseudo-progression (due to increased immune cell infiltration rather than a real disease progression) that should be hypothesized and recognized by clinicians for an adequate disease management.

\section{Programmed death-1/programmed death ligand 1 pathway}

The PD-1/PD-L1 pathway has a crucial role in the regulation of T-cell activity during inflammatory processes. PD-1 is a transmembrane glycoprotein T-cell co-inhibitory receptor, expressed on activated CD4+ and CD8+ T-cells, B-lymphocytes, NK cells, and monocytes within $24 \mathrm{~h}$ from immune system activation by various cytokines (including IL-2, IL-7, IL-15 and IL-21) to mediate immunosuppression by limiting the immune cells lytic activity. ${ }^{54}$ In contrast to CTLA-4 that inhibits T-cells activation during the priming phase of T-cell activation, PD-1 exerts its

Table 1. Completed phase I-III clinical trials of CTLA-4 inhibitors alone or in combination with other agents in metastatic castration-resistant prostate cancer.

\begin{tabular}{|c|c|c|c|c|}
\hline Study agent & Reference & Sample size (n) & Key studies & Results \\
\hline $\begin{array}{l}\text { Ipilimumab with or without } R T \\
\text { [CA184-107] }\end{array}$ & Slovin et al., $2013^{38}$ & 71 & $\begin{array}{l}\text { A phase I/II study to assess safety of } \\
\text { ipilimumab alone or with RT in patients } \\
\text { with mCRPC with or without prior } \\
\text { chemotherapy }\end{array}$ & PSA decline > $50 \%: 16 \%$ \\
\hline Ipilimumab with ADT & Tollefson et al., $2013^{39}$ & 108 & $\begin{array}{l}\text { A randomized, phase II study comparing } \\
\text { a single dose of ipilimumab with } \mathrm{ADT} \\
\text { versus } \mathrm{ADT} \text { alone in patients with } \mathrm{mCRPC}\end{array}$ & $\begin{array}{l}\text { Patients receiving ipilimumab } \\
\text { with ADT were more likely to } \\
\text { have undetectable PSA levels by } \\
3 \text { months ( } 55 \text { versus } 38 \% \text { ) }\end{array}$ \\
\hline $\begin{array}{l}\text { Ipilimumab with or without } \\
\text { docetaxel }\end{array}$ & Small et al., $2006^{43}$ & 43 & $\begin{array}{l}\text { A randomized, phase II study comparing } \\
\text { ipilimumab alone or with docetaxel } \\
\text { in chemotherapy-naïve patients }\end{array}$ & $\begin{array}{l}\text { Co-administration of docetaxel } \\
\text { did not enhance activity of } \\
\text { ipilimumab }\end{array}$ \\
\hline
\end{tabular}

\begin{tabular}{|c|c|c|c|c|}
\hline $\begin{array}{l}\text { Ipilimumab following RT } \\
\text { [CA184-043] }\end{array}$ & Kwon et al., $2014^{44}$ & 799 & $\begin{array}{l}\text { A randomized, phase III trial comparing } \\
\text { ipilimumab versus placebo following } \\
\text { RT in patients with mCRPC previously } \\
\text { treated with docetaxel }\end{array}$ & $\begin{array}{l}\text { The primary end point was not } \\
\text { met [OS: } 11.2 \text { versus } 10 \text { months } \\
\text { HR } 0.85 ; \mathrm{P}=0.053 \text { ] } \\
\text { Improvement } \mathrm{PFS} \text { [ } 4 \text { versus } 3.1 \\
\text { months; } \mathrm{HR} 0.70 ; \mathrm{P}<0.0001] \\
\text { and in } \mathrm{PSA} \text { response [ } 13.1 \\
\text { versus } 5.2 \% \text { ] }\end{array}$ \\
\hline Ipilimumab with PROSTVAC & $\begin{array}{l}\text { Madan et al., 2012 } \\
\text { Jochems et al., 201441 }\end{array}$ & 30 & $\begin{array}{l}\text { A phase I dose-escalation trial assessing } \\
\text { safety/tolerability of ipilimumab with } \\
\text { PROSTVAC in patients with mCRPC }\end{array}$ & $\begin{array}{l}\text { PSA level decrease: } 58 \% \\
\text { and } \\
\text { PSA decline > }>50 \%: 25 \%\end{array}$ \\
\hline Ipilimumab with GVAX & Van den Eertwegh et al., $2012^{42}$ & 28 & $\begin{array}{l}\text { A phase I dose-escalation trial using } \\
\text { one GVAX priming dose combined } \\
\text { with ipilimumab in patients with mCRPC }\end{array}$ & PSA decline > $50 \%: 25 \%$ \\
\hline Ipilimumab with GM-CSF & Fong et al., $2009^{43}$ & 24 & $\begin{array}{l}\text { A phase I dose-escalation trial assessing } \\
\text { safety/tolerability of ipilimumab with } \\
\text { a fixed dose of GM-CSF }\end{array}$ & PSA decline > $50 \%: 50 \%$ \\
\hline Tremelimumab with $A D T$ & McNeel et al., $2012^{47}$ & 11 & $\begin{array}{l}\text { A phase I dose-escalation trial assessing } \\
\text { safety/tolerability of tremelimumab } \\
\text { in combination with bicalutamide }\end{array}$ & $\begin{array}{l}\text { No significant increase in PSA } \\
\text { doubling time }\end{array}$ \\
\hline
\end{tabular}

RT, radiotherapy; mCRPC, metastatic castration-resistant prostate cancer; PSA, prostate-specific antigen; ADT, androgen deprivation therapy; OS, overall survival; HR, hazard ratio; PFS, progression-free survival; GMCSF, granulocyte-macrophage colony-stimulating factor. 
inhibitory activity during the effector phase of T-cell activation in peripheral tissues and tumor microenvironment. Therefore, PD-1 receptor acts as a negative checkpoint regulator, preventing T-cells activation. The interaction between PD-1 and its major ligand PD-L1 (also called B7-H1 or CD274 - the predominant mediator of immunosuppression) leads to inactivation of effector molecules (i.e., Syk in Bcells and Zap70 in T-cells), and inhibition of T-cells proliferation, thus limiting the inflammatory damage of surrounding tissues. Moreover, PD-1/PD-L1 interaction prevents autoimmunity by promoting CD4+ Tcell differentiation into Treg. 55,56

The PD-1/PD-L1 axis strongly contributes to tumor development and progression, representing a mechanism letting tumors to escape from the host's immune system. PD-L1 is over-expressed in cancer cells, stromal cells and TILs of the tumor microenvironment, supporting tumor immune evasion. ${ }^{57}$ In addiction, PD-1 is usually expressed at high levels on tumor-infiltrating Treg, enhancing their proliferation after ligand binding and promoting tumor growth by dampening the immune system.

Therefore, the blockade of PD-1/PD-L1 pathway (via mAbs against PD-1 or PD-L1) may reinforce anti-tumor immune response by stimulating the activity of effector T-cells against cancer cells and tumor microenvironment and diminishing the suppressive activity of intratumoral Treg. ${ }^{10,58}$ The strength of this biological rationale has been confirmed with the outstanding results achieved in the clinical setting with monoclonal antibodies that disrupt the PD-1/PD-L1 interaction (i.e., nivolumab, pembrolizumab, atezolizumab). Significant prolongation of survival, impressive long-lasting responses, and relevant improvements in clinical outcomes with PD-1/PD-L1 inhibitors has been observed in different solid tumors [including melanoma, ${ }^{59,60}$ nonsmall-cell lung cancer, ${ }^{61,62}$ renal-cell carcinoma ${ }^{63}$ in the last years.

Our attention is now facing two major pressing clinical issues: the first one, in the context of cancer with proven efficacy of anti-PD-1/PDL1, the identification of predictive markers that enables to identify the tumor subpopulation most likely to benefit from the therapy; the second one , the search for other types of cancers (mainly at high mutation load) in which immunotherapy with checkpoint inhibitors could radically change the patient's prognosis.

As concern the potential predictors of response to anti-PD-1 pathway, tumor PD-L1 expression, frequently linked with lymphocytes PD-1 expression, has been postulated as the single factor most closely associated to aggressive tumor behavior and anti-PD1 blockade response. ${ }^{64-}$
${ }^{66}$ However, the conflicting results overturn the prognostic significance of tumor PD-L1 expression and its role as a predictor of treatment response. ${ }^{67-69}$ Certainly, the lack of a unique and validated method to evaluate the PD-1/PD-L1 expression, as well as the absence of a prespecified score system to assess PD-1/PD-L1 positivity, can (at least partially) contribute to the lack of conclusive data.

Recently, efforts are directed to assess the role of PD-1/PD-L1 axis in PC, so as to support the potential development of therapies targeting this signaling pathway in setting.

As well as for other tumor types, evidence regarding the expression of PD-L1 on tumor cells is heterogeneous and contradictory also in PC.

Taube and colleagues showed a strong association between the immunohistochemical PD-L1 expression and the likelihood of response to PD-1 blockade in a cohort of different malignancies. However, the negative PD-L1 staining of the small subgroup of CRPC samples (only 2 patients) included in this analysis, did not allow to draw definitive conclusions. ${ }^{64,66} \mathrm{~A}$ rare PD-L1 expression from primary prostate tumors has been recently reported. Interestingly, PC PD-L1 expression seems to be independent from PTEN loss (whereas several studies have suggested that PTEN loss induces PD-L1 up-regulation as a mechanism of innate immune resistance), therefore assuming a role of adaptive immune resistance in mitigating antitumor immune responses. ${ }^{70}$

Conversely, we reported a relevant percentage of PC cells PD-L1 expression (50\%-19\% were scored 2+) and TIL PD-1 expression (56\%$19 \%$ scored as $2+$ ) in a series of 16 CRPC patients. ${ }^{71}$

Accordingly, a high expression of PD-1 has been demonstrated in CD8+ prostate-infiltrating T lymphocytes (thus unable to mount an effective immune response).$^{72}$ Moreover, recently Gevensleben and Colleagues for the first time extensively evaluated the expression of PD-L1 on primary radical prostatectomy specimens ( $\mathrm{n}=873$ samples) from hormone-treatment-naïve patients using a newly validated mAb against PD-L1 (clone EPR1161(2)) and a semi-quantitative scoring system of staining intensity. This study showed an elevated PD-L1 expression (52.2 and $61.7 \%$ in the two cohorts analyzed, respectively) in PC samples, with a correlation between PD-L1 expression and Ki-67 proliferation marker, androgen receptor expression, and significantly shorter biochemical-recurrence free survival (regardless of tumor stage, PSA levels, Gleason score and surgical margins). ${ }^{73}$ The poor prognostic role of PD-L1 expression confirms the capacity of PD-L1 to promote tumor recurrence by exhausting antitumor immunity.

Noteworthy, CRPC patients resistant to enzalutamide displayed

Table 2. Selected ongoing studies of CTLA-4 alone and in combination in prostate cancer (www.clinicaltrials.gov).

\begin{tabular}{|c|c|c|c|c|c|c|}
\hline Study agent & Phase & Description & $\begin{array}{l}\text { Primary } \\
\text { endpoints }\end{array}$ & Patient population & Clinical Trial gov ID & $\begin{array}{l}\text { Trial status } \\
\text { (sample size) }\end{array}$ \\
\hline $\begin{array}{l}\text { Ipilimumab } \\
\text { [CA184-095] }\end{array}$ & III & Ipilimumab versus placebo & OS & $\begin{array}{l}\text { Chemotherapy-na ve } \\
\text { mCRPC patients }\end{array}$ & NCT01057810 & $\begin{array}{l}\text { Completed } \\
\text { (602 patients) }\end{array}$ \\
\hline Ipilimumab & II & $\begin{array}{l}\text { Ipilimumab } 3 \mathrm{mg} / \mathrm{kg} \text { versus } \\
\text { ipilimumab } 10 \mathrm{mg} / \mathrm{kg}\end{array}$ & $\begin{array}{l}\text { Radiological } \\
\text { PFS }\end{array}$ & $\begin{array}{l}\text { Chemotherapy-na ve } \\
\text { mCRPC patients }\end{array}$ & NCT02279862 & $\begin{array}{l}\text { Active, not recruiting } \\
\text { (50 patients) }\end{array}$ \\
\hline Ipilimumab & II & $\begin{array}{l}\text { Ipilimumab plus leuprolide } \\
\text { acetate }\end{array}$ & $\begin{array}{l}\text { Immunological } \\
\text { variables } \\
\text { measurements }\end{array}$ & $\begin{array}{l}\text { Patients with prostate } \\
\text { cancer before radical } \\
\text { prostatectomy } \\
\text { (neoadjuvant setting) }\end{array}$ & NCT01194271 & $\begin{array}{l}\text { Completed } \\
\text { (19 patients) }\end{array}$ \\
\hline $\begin{array}{l}\text { Ipilimumab } \\
\text { plus ADT }\end{array}$ & II & $\begin{array}{l}\text { Ipilimumab plus leuprolide } \\
\text { or goserelin or degaralix }\end{array}$ & PSA response & $\begin{array}{l}\text { Chemotherapy-naïve } \\
\text { mCRPC patients }\end{array}$ & NCT01377389 & $\begin{array}{l}\text { Active, not recruiting } \\
\text { ( } 48 \text { patients) }\end{array}$ \\
\hline $\begin{array}{l}\text { Ipilimumab } \\
\text { plus } \mathrm{AA}\end{array}$ & $\mathrm{I} / \mathrm{II}$ & Ipilimumab plus AA plus PDN & PFS and safety & $\begin{array}{l}\text { Chemotherapy- and } \\
\text { immunotherapy-naïve } \\
\text { mCRPC patients }\end{array}$ & NCT01688492 & $\begin{array}{l}\text { Active, not recruiting } \\
\text { (50 patients) }\end{array}$ \\
\hline $\begin{array}{l}\text { Ipilimumab } \\
\text { and sipuleucel-' }\end{array}$ & I & $\begin{array}{l}\text { Ipilimumab following } \\
\text { sipuleucel-T }\end{array}$ & $\begin{array}{l}\text { Immunological } \\
\text { variables } \\
\text { measurements }\end{array}$ & $\begin{array}{l}\text { Chemotherapy-naïve } \\
\text { mCRPC patients }\end{array}$ & NCT01832870 & $\begin{array}{l}\text { Active, not recruiting } \\
\text { ( } 9 \text { patients) }\end{array}$ \\
\hline
\end{tabular}

OS, overall survival; mCRPC, metastatic castration-resistant prostate cancer; PFS, progression-free survival; ADT, androgen deprivation therapy; $\mathrm{AA}$, abiraterone acetate; PDN, prednisone. 
increased levels of PD-L1 positive dendritic cells circulating in blood. Moreover, the mechanisms that mediate CRPC enzalutamide-resistance might depend on both intrinsic and induced expression of PD-L1 from DCs. The tumor intrinsic PD-L1 expression in enzalutamideresistant CRPC did not show classical androgen receptor (AR) activation, suggesting a PD-L1-driven (but not non-AR dependent) resistance to enzalutamide. ${ }^{74}$ In addition, important data suggest the pivotal function of PC microenvironment in negatively modulating the immune system response against cancer cells. Clusters of FOXP3+, PD-1+, and B7-H1+ lymphocytes (implicated in the inhibition and exhaustion of Tcells) have been detected nearby PC lesions, thereby contributing to ineffective anticancer immune responses. ${ }^{24}$ Moreover, tumor-associate stromal myofibroblasts substantially contribute to an immunosuppressive status of the PC microenvironment by releasing several stromal factors (CCL2, IL-6, TGF $\beta$ ) that induce monocyte differentiation into dendritic cells (DCs) with an immunosuppressive phenotype (CD14+, PD-L1+ DCs). ${ }^{75}$ Therefore, targeting tumor-associated stromal cells could represent a promising strategy to strengthen anticancer immune system. As regards the activity of molecules that disrupt the PD1/PD-L1 interaction in PC patients, data are widely immature. In the large phase I trial testing the safety and activity of the anti-PD1 antibody nivolumab in a cohort of 296 patients with advanced solid tumors, no objective responses were described in the small subgroup of $17 \mathrm{mCRPC}$ patients (one patient had a $28 \%$ reduction in measurable lesions). Two of the 17 mCRCP tissue specimens were eligible for immunohistochemical analysis, both of which were negative for PD-L1 expression. ${ }^{76}$ Obviously this sample size is considerably too small (17 cases of CRPC and only 2 PC samples worthy to immunohistochemical analysis) to support or rule out further investigations on the role of anti- PD-1/PDL1 molecules for PC treatment. Several trials are currently evaluating the activity of targeting the PD-1/PD-L1 pathway. A Phase 1b, doseescalation ongoing study of nivolumab (MDX-1106) aims at determining the safety and effectiveness of this anti-PD-1 agent in patients with certain types of cancer, including PC (NCT00730639).

An interesting biomarker-driven phase 2 trial of combined PD-1 and CTLA-4 blockade in AR-V7 positive metastatic CRPC (mCRPC) patients is testing the association of nivolumab and ipilimumab in this specific subset of patients (NCT02601014).

The anti-PD1 antibody pembrolizumab is under evaluation as single agent in mCRPC patients previously treated with enzalutamide (NCT02312557), in combination with pTVG-HP plasmid DNA vaccine in mCRPC patients (NCT02499835), in association with cryosurgery in treating patients with newly diagnosed, oligo-metastatic PC (NCT02489357), and combined with ADXS31-142 (a Listeria monocytogenes/PSA [Lm-LLO-PSA] vaccine [ADXS-PSA]) in pre-treated mCRPC patients (NCT02325557). CT-011, an anti-PD-1 antibody, is being assessed in a phase II trial in combination with sipuleucel-T and lowdose cyclophosphamide in advanced CRPC patients (NCT01420965).

Several issues need to be clarified to guide a more rational targeted therapy strategy: if prostate cancer PD-L1 expression be considered a poor prognostic marker and/or a predictive marker of response to antiPD-L1 therapy; if ADT down-regulates steadily tumor PD-L1 expression, and therefore if it is more appropriate to address an anti-PD-1 therapy for a disease naïve to hormone therapies or whether on the contrary to an advanced castration resistant disease assuming the activation of PD-1/PD-L1 pathway as a mechanism to escape ADT.

\section{Other immune checkpoint molecules - potential targets for inhibition}

The impressive improvements in immunology have led to the identification of immune checkpoint proteins others than CTLA-4 and PD-
1/PD-L1, expressed on T cells (and aberrantly on cancer cells) that trigger inhibitory pathways dampening T-cell activity.

Developing molecules that inhibit immune checkpoint proteins, thus enhancing the anti-tumor immunity, represents one of the main anticancer challenges.

\section{B7 proteins}

The B7 family includes proteins that interact with known or still unknown receptors to regulate T lymphocyte activation and function.

While the interaction between B7-1 (CD80) and B7-2 (CD86) costimulatory ligands (expressed on APC) with CD28 (expressed on T lymphocytes) is well known to result in enhanced T-cell activation, and the B7-H1 (PD-L1)/PD1 interaction dampens T-cells activity, the precise role of the other B7 ligands (B7-H2, B7-H3, B7-H4, V-domain Ig suppressor of T cell activation [VISTA], and B7-H6) is far from being intimately understood. ${ }^{77}$

As regards $\mathrm{B} 7-\mathrm{H} 3$ and $\mathrm{B} 7-\mathrm{H} 4$, although many issues remain unresolved (identification of the receptor to which they bind, the physiological role of B7-H3 - immune-stimulatory or immune-suppressive), it appears that both of these molecules are implicated in immune-modulatory processes of the tumor microenvironment favoring cancer development. ${ }^{78}$

\section{B7-H3}

B7-H3 (also termed CD276) is a type I transmembrane protein, preferentially expressed on recently activated monocytes, T cells, B cells, and NK cells. The receptor(s) for B7-H3 has not yet been identified, and analogously B7-H3 functions are far from being conclusively understood. In fact, B7-H3 has been described to have opposite immune-modulatory functions (both stimulatory and inhibitory) depending on the different receptor that it binds. The stimulatory role of B7-H3 consists in promoting T-cell proliferation and IFN $-\gamma$ expression, while the inhibitory functions depend on the B7-H3-mediated inhibition of cytokine production, impairment of type I T-helper cell responses, and restriction of NK-mediated cytolysis. ${ }^{77,79}$

Over-expression of B7-H3 has been reported in several tumor types, with an interesting association to more aggressive tumor biology (low count of tumor infiltrating lymphocytes, high tumor grade and stage, metastatic spreading)..$^{79-82}$

PC expresses aberrant levels of B7-H3 ${ }^{78,80,83,84}$ PC cell surface B7-H3 expression is known to correlate with aggressive histopathologic features (larger tumor volume, extra-prostatic extension, seminal vesicle infiltration, higher Gleason score), ${ }^{83,85}$ proliferation markers, ${ }^{85}$ increased risk of tumor recurrence and progression, ${ }^{83,85,86}$ disease spread and poor clinical outcomes. ${ }^{78,80}$

Interestingly, B7-H3 acts in stimulating tumor progression both via its immune-regulatory properties (blockade of Treg proliferative activity leading to tumor evasion of the immune system) and through a direct pro-oncogenic role (altered tumor cells interactions with adhesion molecules, resulting in enhanced tumor cells migration and invasiveness, and increased Tem-mediated vascularization). ${ }^{84,86}$ Moreover, B7-H3 is expressed also in bone metastases and hormone-resistant PC specimens, and remains stable during ADT. ${ }^{87}$ Therefore, the poor prognostic role of $\mathrm{B} 7-\mathrm{H} 3$ along with its expression independent from hormonal regulation support $\mathrm{B} 7-\mathrm{H} 3$ as a promising therapeutic target (also during or after ADT).

\section{B7-H4}

B7-H4 (also known as B7S1, B7×, and Vtcn1) is a type I transmembrane protein, whose receptor is still undetermined, expressed on activated APCs and on cancer cells, where it exerts co-inhibitory functions impairing T-cells proliferation and IL-2 production and constraining the 
expansion of neutrophil progenitors. ${ }^{61,77}$

The over-expression of B7-H4 has been directly implicated in cancer cells growth. The tumor expression of this T-cell co-inhibitory ligand, able to induce immunosuppression, thereby facilitating cancer progression, has been related with more aggressive cancer behavior (high tumor burden, advanced tumor stage, increased neo-angiogenesis) and poor clinical outcome in different tumors. ${ }^{88-92}$

An immunohistochemical analysis of B7-H4 expression revealed a diffusely positive cytoplasm and/or membrane staining in PC tissue compared to healthy prostate tissue, with a positive correlation with higher tumor grade..$^{93}$

However, an interesting analysis of B7-H3 and B7-H4 expression in a murine model of spontaneous PC, although confirming the B7-H3 and B7-H4 role as biomarkers of PC (significantly elevated expression and association with cancer progression), yet it highlighted the absence of a significant impact of B7-H4 in tumor development. In fact, mice lacking B7-H3 showed a dramatic PC progression, while tumor growth was independent from B7-H4 expression. ${ }^{94}$

\section{TIM 3}

T cell immunoglobulin domain and mucin domain-containing molecule 3 (TIM3) is a recently discovered negative immunomodulatory molecule, preferentially expressed on differentiated T-helper 1 (Th1) CD4+ T lymphocytes (but not on Th2 cells). The interaction between TIM3 (the receptor) and its ligand (galectin-9) causes negative regulation of Th1 immunity (inhibition of Th1 and Th17 responses), induction of peripheral tolerance, and phagocytosis of apoptotic cells. ${ }^{95}$ TIM3 stimulates cancer progression, maintaining the tumor immunosuppressive microenvironment status by inducing $\mathrm{T}$ cell exhaustion. Indeed, recent evidences have shown an over-expression of TIM3 on CD4+ and CD8+ T cells in different cancer types (including NSCLC, melanoma, and ovarian patients), ${ }^{96-98}$ suggesting its role as a potential therapeutic target for stimulate anti-cancer immune response. Piao and Colleagues reported an elevated expression of TIM3 on both CD4+ $\mathrm{T}$ and CD8+ $\mathrm{T}$ cells also in peripheral blood as well as within tumor tissue specimens of PC patients, with a robust correlation with advanced disease stage (Gleason score, PSA levels, metastatic spread) and poor prognosis patients. ${ }^{99}$ In preclinical models, blockade of both PD-1 and TIM3 enhanced antitumor immune responses, supporting TIM3 as a new potential target for therapy.

\section{Conclusions}

In conclusion, $\mathrm{PC}$ represents an interesting setting for the development of immune checkpoint inhibitors, considered the intrinsic immune-stimulating properties of this tumor and the immune-modulating activities of conventional PC treatments (especially ADT). Future goals aim to delineate the precise setting of treatment (adjuvant, metastatic hormone-naïve disease, mCRPC), to investigate potential synergistic effect of combinations with other therapies (hormonal agents, chemotherapy, radiotherapy, other immunotherapies), to outline the proper therapeutic algorithm, and to develop a biomarker driven therapy that reserves immune checkpoint inhibitors only to those patients with high probability of response.

\section{References}

1. Ferlay J, Soerjomataram I, Dikshit R, et al. Cancer incidence and mortality worldwide: sources, methods and major patterns in GLOBOCAN 2012. Int J Cancer 2015;136:E359-86.
2. de Bono JS, Oudard S, Ozguroglu M, et al. Prednisone plus cabazitaxel or mitoxantrone for metastatic castration-resistant prostate cancer progressing after docetaxel treatment: a randomised openlabel trial. Lancet 2010;376:1147-54.

3. Fizazi K, Scher HI, Molina A, et al. Abiraterone acetate for treatment of metastatic castration-resistant prostate cancer: final overall survival analysis of the COU-AA-301 randomised, double-blind, placebo-controlled phase 3 study. Lancet Oncol 2012;13:983-92.

4. Ryan CJ, Smith MR, Fizazi K, et al. Abiraterone acetate plus prednisone versus placebo plus prednisone in chemotherapy-naive men with metastatic castration-resistant prostate cancer (COU-AA302): final overall survival analysis of a randomised, double-blind, placebo-controlled phase 3 study. Lancet Oncol 2015;16:152-60.

5. Scher HI, Fizazi K, Saad F, et al. Increased survival with enzalutamide in prostate cancer after chemotherapy. N Engl J Med 2012;367:1187-97.

6. Beer TM, Armstrong AJ, Rathkopf DE, et al. Enzalutamide in metastatic prostate cancer before chemotherapy. N Engl J Med 2014;371:424-33.

7. Parker C, Nilsson S, Heinrich D, et al. Alpha emitter radium-223 and survival in metastatic prostate cancer. $\mathrm{N}$ Engl $\mathrm{J}$ Med 2013;369:213-23.

8. Hanahan D, Weinberg RA. Hallmarks of cancer: the next genera tion. Cell 2011;144:646-74.

9. Dunn GP, Bruce AT, Ikeda $\mathrm{H}$, et al. Cancer immunoediting: from immunosurveillance to tumor escape. Nat Immunol 2002;3:991-98.

10. Pardoll DM. The blockade of immune checkpoints in cancer immunotherapy. Nat Rev Cancer 2012;12:252-64.

11. Massari F, Santoni M, Ciccarese $\mathrm{C}$ et al. The immunocheckpoints in modern oncology: the next 15 years. Exp Opin Biol Ther 2015;15:917-21.

12. Kantoff PW, Higano CS, Shore ND, et al. Sipuleucel-T immunotherapy for castration-resistant prostate cancer. N Engl J Med 2010;363:411-22.

13. Cheng ML, Fong L. Beyond sipuleucel-T: immune approaches to treating prostate cancer. Curr Treat Options Oncol 2014;15:115-26.

14. Wang X, Yu J, Sreekumar A, et al. Autoantibody signatures in prostate cancer. N Engl J Med 2005;353:1224-35.

15. Coffey DS, Isaacs JT. Prostate tumor biology and cell kinetics-theory. Urology 1981;17:40-53.

16. Westdorp H, Sköld AE, Snijer BA, et al. Immunotherapy for prostate cancer: lessons from responses to tumor-associated antigens. Front Immunol 2014;5:191.

17. Ozu C, Nakashima J, Horiguchi Y, et al. Prediction of bone metastases by combination of tartrate-resistant acid phosphatase, alkaline phosphatase and prostate specific antigen in patients with prostate cancer. Int J Urol 2008;15:419-22.

18. Gu Z, Thomas G, Yamashiro J, et al. Prostate stem cell antigen (PSCA) expression increases with high Gleason score, advanced stage and bone metastasis in prostate cancer. Oncogene. 2000;19:1288-96.

19. Ebelt K, Babaryka G, Figel AM, et al. Dominance of CD4+ lymphocytic infiltrates with disturbed effector cell characteristics in the tumor microenvironment of prostate carcinoma. Prostate 2008;68:1-10.

20. Gannon PO, Poisson A0, Delvoye N, et al. Characterization of the intra-prostatic immune cell infiltration in androgen-deprived prostate cancer patients. J Immunol Methods 2009;348:9-17.

21. Vesalainen S, Lipponen P, Talja M, et al. Histological grade, perineural infiltration, tumour-infiltrating lymphocytes and apoptosis as determinants of long-term prognosis in prostatic adenocarcinoma. Eur J Cancer 1994;30A:1797-803.

22. Hussein MR, Al-Assiri M, Musalam AO. Phenotypic characterization of the infiltrating immune cells in normal prostate, benign 
nodular prostatic hyperplasia and prostatic adenocarcinoma. Exp Mol Pathol 2009;86:108-13.

23. Bronte V, Kasic T, Gri G, et al. Boosting antitumor responses of T lymphocytes infiltrating human prostate cancers. J Exp Med 2005;20:1257-68.

24. Ebelt K, Babaryka G, Frankenberger B, et al. Prostate cancer lesions are surrounded by FOXP3+, PD-1+ and B7-H1+ lymphocyte clusters. Eur J Cancer 2009;45:1664-72.

25. Kiniwa Y, Miyahara Y, Wang HY, et al. CD8+ Foxp3+ regulatory T cells mediate immunosuppression in prostate cancer. Clin Cancer Res. 2007;13:6947-58.

26. Kärjä V, Aaltomaa S, Lipponen P, et al. Tumour-infiltrating lymphocytes: A prognostic factor of PSA-free survival in patients with local prostate carcinoma treated by radical prostatectomy. Anticancer Res 2005;25:4435-38.

27. Davidsson S, Ohlson AL, Andersson S0, et al. CD4 helper T cells, CD8 cytotoxic T cells, and FOXP3(+) regulatory T cells with respect to lethal prostate cancer. Mod Pathol 2013;26:448-55.

28. Tang S, Moore ML, Grayson JM, et al. Increased CD8+ T-cell function following castration and immunization is countered by parallel expansion of regulatory T cells. Cancer Res 2012;72:1975-85.

29. Flammiger A, Weisbach $\mathrm{L}$, Huland $\mathrm{H}$, et al. High tissue density of FOXP3+ T cells is associated with clinical outcome in prostate cancer. Eur J Cancer 2013;49:1273-79.

30. Sutherland JS, Goldberg GL, Hammett MV, et al. Activation of thymic regeneration in mice and humans following androgen blockade. J Immunol 2005;175:2741-53.

31. Wilson CA, Mrose SA, Thomas DW. Enhanced production of B lymphocytes after castration. Blood 1995;85:1535-39.

32. Drake CG, Doody AD, Mihalyo MA, et al. Androgen ablation mitigates tolerance to a prostate/prostate cancer-restricted antigen. Cancer Cell 2005;7:239-49.

33. Mercader M, Bodner BK, Moser MT, et al. T cell infiltration of the prostate induced by androgen withdrawal in patients with prostate cancer. Proc Natl Acad Sci U S A 2001;98:14565-70.

34. Antonarakis ES, Kibel A, Tyler RC, et al. Randomized phase II trial evaluating the optimal sequencing of sipuleucel-T and androgen-deprivation therapy (ADT) in patients (pts) with biochemically recurrent prostate cancer (BRPC). J Clin Oncol 2013;suppl 6:abstr 34.

35. Collins AV, Brodie DW, Gilbert RJ, et al. The interaction properties of costimulatory molecules revisited. Immunity 2002;17:201-10.

36. Rudd CE, Taylor A, Schneider H. CD28 and CTLA-4 coreceptor expression and signal transduction. Immunol Rev 2009;229:12-26.

37. Wing K, Yamaguchi T, Sakaguchi S. Cell-autonomous and -nonautonomous roles of CTLA-4 in immune regulation. Trends Immunol 2011;32:428-33.

38. Demaria S, Ng B, Devitt ML, et al. Ionizing radiation inhibition of distant untreated tumors (abscopal effect) is immune mediated. Int J Radiat Oncol 2004;58:862-70.

39. Demaria S, Kawashima N, Yang AM, et al. Immune-mediated inhibition of metastases after treatment with local radiation and CTLA4 blockade in a mouse model of breast cancer. Clin Cancer Res 2005;11:728-34.

40. Dewan MZ, Galloway AE, Kawashima N, et al. Fractionated but not single-dose radiotherapy induces an immune-mediated abscopal effect when combined with anti-CTLA-4 antibody. Clin Cancer Res 2009;15:5379-88.

41. Finkelstein SE, Salenius S, Mantz CA, et al. Combining immunotherapy and radiation for prostate cancer. Clin Genitourin Cancer 2015;13:1-9.

42. Sharabi AB, Lim M, DeWeese TL, et al. Radiation and checkpoint blockade immunotherapy: radiosensitisation and potential mechanisms of synergy. Lancet Oncol 2015;16:e498-509.

43. Slovin SF, Higano CS, Hamid 0, et al. Ipilimumab alone or in com- bination with radiotherapy in metastatic castration-resistant prostate cancer: results from an open-label, multicenter phase I/II study. Ann Oncol 2013;24:1813-21.

44. Tollefson MK, Thompson RH, Granberg CF, et al. A randomized phase II study of ipilimumab with androgen ablation compared with androgen ablation alone in patiets with advanced prostate cancer. Genitourinary Cancer Symposium Meeting 2010;abstr 168.

45. Madan RA, Mohebtash M, Arlen PM, et al. Ipilimumab and a poxviral vaccine targeting prostate-specific antigen in metastatic castration-resistant prostate cancer: a phase 1 dose-escalation trial. Lancet Oncol 2012;13:501-8.

46. Jochems C, Tucker JA, Tsang KY, et al. A combination trial of vaccine plus ipilimumab in metastatic castration-resistant prostate cancer patients: immune correlates. Cancer Immunol Immunother 2014;63:407-18.

47. van den Eertwegh AJ, Versluis J, van den Berg HP, et al. Combined immunotherapy with granulocyte-macrophage colony-stimulating factor-transduced allogeneic prostate cancer cells and ipilimumab in patients with metastatic castration-resistant prostate cancer: a phase 1 dose-escalation trial. Lancet Oncol 2012;13:509-17.

48. Fong L, Kwek SS, O'Brien S, et al. Potentiating endogenous antitumor immunity to prostate cancer through combination immunotherapy with CTLA4 blockade and GM-CSF. Cancer Res 2009;69:609-15.

49. Small E, Higano C, Tchekmedyian N, et al. Randomized phase II study comparing 4 monthly doses of ipilimumab (MDX-010) as a single agent or in combination with a single dose of docetaxel in patients with hormone-refractory prostate cancer. ASCO Meeting Abstracts. 2006;24:4609.

50. Kwon ED, Drake CG, Scher HI, et al. Ipilimumab versus placebo after radiotherapy in patients with metastatic castration-resistant prostate cancer that had progressed after docetaxel chemotherapy (CA184-043): a multicentre, randomised, double-blind, phase 3 trial. Lancet Oncol 2014;15:700-12.

51. Kittai A, Meshikhes M, Aragon-Ching JB. Ipilimumab: a potential immunologic agent in the treatment of metastatic castration-resistant prostate cancer. Cancer Biol Ther 2014;15:1299-300.

52. Parker C. A near miss for prostate cancer immunotherapy. Lancet Oncol 2014;15:669-71.

53. McNeel DG, Smith HA, Eickhoff JC, et al. Phase I trial of tremelimumab in combination with short-term androgen deprivation in patients with PSA-recurrent prostate cancer. Cancer Immunol Immunother 2012;61:1137-47.

54. Agata Y, Kawasaki A, Nishimura H, et al. Expression of the PD-1 antigen on the surface of stimulated mouse T and B lymphocytes. Int Immunol 1996;8:765-72.

55. Blank C, Brown I, Peterson AC, et al. PD-L1/B7H-1 inhibits the effector phase of tumor rejection by $\mathrm{T}$ cell receptor (TCR) transgenic CD8+ T cells. Cancer Res 2004;64:1140-5.

56. Dong H, Strome SE, Salomao DR, et al. Tumor-associated B7-H1 promotes T-cell apoptosis: a potential mechanism of immune evasion. Nat Med 2002;8:793-800.

57. Zou W, Chen L. Inhibitory B7-family molecules in the tumor microenvironment. Nat Rev Immunol 2008;8:467-77.

58. Topalian SL, Drake CG, Pardoll DM. Targeting the PD-1/B7-H1(PDL1) pathway to activate anti-tumor immunity. Curr Opin Immunol 2012;24:207-12.

59. Robert C, Long GV, Brady B, et al. Nivolumab in previously untreated melanoma without BRAF mutation. N Engl J Med 2015;372:320-30.

60. Robert C, Schachter J, Long GV, et al. Pembrolizumab versus ipilimumab in advanced melanoma. N Engl J Med 2015;372:2521-32.

61. Borghaei H, Paz-Ares L, Horn L, et al. Nivolumab versus docetaxel in advanced non squamous non-small-cell lung cancer. $\mathrm{N}$ Engl $\mathrm{J}$ Med 2015;373:1627-39. 
62. Brahmer J, Reckamp KL, Baas P, et al. Nivolumab versus docetaxel in advanced squamous-cell non-small-cell lung cancer. $\mathrm{N}$ Engl $\mathrm{J}$ Med 2015;373:123-35.

63. Motzer RJ, Escudier B, McDermott DF, et al. Nivolumab versus everolimus in advanced renal-cell carcinoma. $\mathrm{N}$ Engl $\mathrm{J}$ Med 2015;373:1803-13.

64. Taube JM, Klein A, Brahmer JR, et al. Association of PD-1, PD-1 ligands, and other features of the tumor immune microenvironment with response to anti-PD-1 therapy. Clin Cancer Res 2014;20:5064-74.

65. Iacovelli R, Nolè F, Verri E, et al. Prognostic role of PD-L1 expression in renal cell carcinoma. A systematic review and meta-analysis. Target Oncol 2016;11:143-8.

66. Grosso J, Horak CE, Inzunza D, et al. Association of tumor PD-L1 expression and immune biomarkers with clinical activity in patients (pts) with advanced solid tumors treated with nivolumab (anti- PD-1; BMS-936558; 0NO-4538). J Clin Oncol 2013;31 suppl:abstr 3016.

67. Fay AP, Callea M, Gray KP, et al. PD-L1 expression in non-clear cell renal cell carcinoma. J Clin Oncol 2014;32 suppl 4:abstr 424.

68. Madore J, Vilain R, Menzies AM, et al. PD-L1 expression in melanoma shows marked heterogeneity within and between patients: implications for anti-PD-1/PD-L1 clinical trials. Pigment Cell Melanoma Res 2015;28:245-53.

69. Shim H-J, Hwang J-E, Jung S-I, et al. Clinical impact of programmed cell death ligand 1 (PD-L1), programmed cell death 1 (PD-1), and CD8 expression in pancreatic cancer. J Clin Oncol 2014;32suppl:abstr e15258.

70. Martin AM, Nirschl TR, Nirschl CJ, et al. Paucity of PD-L1 expression in prostate cancer: innate and adaptive immune resistance. Prostate Cancer Prostatic Dis 2015;18:325-32.

71. Massari F, Ciccarese C, Caliò A, et al. Magnitude of PD-1, PD-L1 and $\mathrm{T}$ lymphocyte expression on tissue from castration-resistant prostate adenocarcinoma: an exploratory analysis. Target Oncol 2015 [Epub ahead of print].

72. Sfanos KS, Bruno TC, Meeker AK, et al. Human prostate-infiltrating CD8+ T lymphocytes are oligoclonal and PD-1+. Prostate 2009;69:1694-703.

73. Gevensleben H, Dietrich D, Golletz C, et al. The immune checkpoint regulator PD-L1 is highly expressed in aggressive primary prostate cancer. Clin Cancer Res 2015 [Epub ahead of print].

74. Bishop JL, Sio A, Angeles A, et al. PD-L1 is highly expressed in enzalutamide resistant prostate cancer. Oncotarget 2014 [Epub ahead of print].

75. Spary LK, Salimu J, Webber JP, et al. Tumor stroma-derived factors skew monocyte to dendritic cell differentiation toward a suppressive CD14+ PD-L1+ phenotype in prostate cancer. Oncoimmunol 2014;3:e955331.

76. Topalian SL, Hodi FS, Brahmer JR, et al. Safety, activity, and immune correlates of anti-PD-1 antibody in cancer. N Engl J Med 2012;366:2443-54.

77. Ceeraz S, Nowak EC, Noelle RJ. B7 family checkpoint regulators in immune regulation and disease. Trends Immunol 2013;34:556-63.

78. Zang X, Thompson RH, Al-Ahmadie HA, et al. B7-H3 and B7x are highly expressed in human prostate cancer and associated with disease spread and poor outcome. Proc Natl Acad Sci U S A 2007;104:19458-63.

79. Katayama A, Takahara M, Kishibe K, et al. Expression of B7-H3 in hypopharyngeal squamous cell carcinoma as a predictive indicator for tumor metastasis and prognosis. Int J Oncol 2011;38:1219-26.

80. Tekle C, Nygren MK, Chen YW, et al. B7-H3 contributes to the metastatic capacity of melanoma cells by modulation of known metastasis-associated genes. Int J Cancer 2012;130:2282-90.

81. Arigami T, Narita N, Mizuno R, et al. B7-h3 ligand expression by primary breast cancer and associated with regional nodal metastasis. Ann Surg 2010;252:1044-51.

82. Wu CP, Jiang JT, Tan M, et al. Relationship between co-stimulatory molecule B7-H3 expression and gastric carcinoma histology and prognosis. World J Gastroenterol 2006;12:457-9.

83. Roth TJ, Sheinin Y, Lohse CM, et al. B7-H3 ligand expression by prostate cancer: a novel marker of prognosis and potential target for therapy. Cancer Res 2007;67:7893-900.

84. Yuan H, Wei X, Zhang G, et al. B7-H3 over expression in prostate cancer promotes tumor cell progression. J Urol 2011;186:1093-99.

85. Liu Y, Vlatkovic L, Sæter T, et al. Is the clinical malignant phenotype of prostate cancer a result of a highly proliferative immune-evasive B7-H3-expressing cell population? Int J Urol 2012;19:749-56.

86. Parker AS, Heckman MG, Sheinin Y, et al. Evaluation of B7-H3 expression as a biomarker of biochemical recurrence after salvage radiation therapy for recurrent prostate cancer. Int J Radiat Oncol Biol Phys 2011;79:1343-49.

87. Chavin G, Sheinin Y, Crispen PL, et al. Expression of immunosuppresive B7-H3 ligand by hormone-treated prostate cancer tumors and metastases. Clin Cancer Res 2009;15:2174-80.

88. Fan M, Zhuang Q, Chen Y, et al. B7-H4 expression is correlated with tumor progression and clinical outcome in urothelial cell carcinoma. Int J Clin Exp Pathol 2014;7:6768-75.

89. Krambeck AE, Thompson RH, Dong H, et al. B7-H4 expression in renal cell carcinoma and tumor vasculature: associations with cancer progression and survival. Proc Natl Acad Sci U S A 2006;103: 10391-96.

90. Liu W, Shibata K, Koya Y, et al. B7-H4 overexpression correlates with a poor prognosis for cervical cancer patients. Mol Clin Oncol 2014;2:219-25.

91. Chen LJ, Sun J, Wu HY, et al. B7-H4 expression associates with cancer progression and predicts patient's survival in human esophageal squamous cell carcinoma. Cancer Immunol Immunother 2011;60:1047-55.

92. Arigami T, Uenosono Y, Hirata M, et al. Expression of B7-H4 in blood of patients with gastric cancer predicts tumor progression and prognosis. J Surg Oncol 2010;102:748-52.

93. Qian Y, Yao HP, Shen L, et al. Expression of B7-H4 in prostate cancer and its clinical significance. Zhejiang Da Xue Xue Bao Yi Xue Ban 2010;39:345-9.

94. Kreymborg K, Haak S, Murali R, et al. Ablation of B7-H3 but not B7$\mathrm{H} 4$ results in highly increased tumor burden in a murine model of spontaneous prostate cancer. Cancer Immunol Res 2015;3:849-54.

95. Sakuishi K, Jayaraman P, Behar SM, et al. Emerging Tim-3 functions in antimicrobial and tumor immunity. Trends Immunol 2011;32:345-9.

96. Gao X, Zhu Y, Li G, et al. TIM-3 expression characterizes regulatory $\mathrm{T}$ cells in tumor tissues and is associated with lung cancer progression. PLoS One 2012;7:e30676.

97. Fourcade J, Sun Z, Benallaoua M, et al. Upregulation of Tim-3 and PD-1 expression is associated with tumor antigen-specific CD8+ T cell dysfunction in melanoma patients. J Exp Med 2010;207:217586.

98. Wu J, Liu C, Qian S, et al. The expression of Tim-3 in peripheral blood of ovarian cancer. DNA Cell Biol 2013;32:648-53.

99. Piao YR, Jin ZH, Yuan KC, et al. Analysis of Tim-3 as a therapeutic target in prostate cancer. Tumour Biol 2014;35:11409-14. 